\title{
BMJ Open Protective effect of smoking against pterygium development in men: a nationwide longitudinal cohort study in South Korea
}

Tyler Hyungtaek Rim, ${ }^{1}$ Dong Wook Kim, ${ }^{2}$ Ching-Yu Cheng, ${ }^{3,4,5}$ Sung Soo Kim ${ }^{1,6,7}$

To cite: Rim TH, Kim DW, Cheng C-Y, et al. Protective effect of smoking against pterygium development in men: a nationwide longitudinal cohort study in South Korea. BMJ Open 2017;7:e017014. doi:10.1136/ bmjopen-2017-017014

- Prepublication history and additional material for this paper are available online. To view these files, please visit the journal online (http://dx.doi. org/10.1136/bmjopen-2017017014).

Received 1 April 2017

Revised 4 July 2017

Accepted 25 July 2017
CrossMark

For numbered affiliations see end of article.

Correspondence to Ching-Yu Cheng; chingyu.cheng@duke-nus.edu. sg and Professor Sung Soo Kim; semekim@yuhs.ac

\section{ABSTRACT}

Objective The present study aimed to evaluate the association between smoking and incident pterygium in adult Korean men.

Design A retrospective nationwide longitudinal cohort. Setting National Health Insurance database of South Korea.

Participants This study included Korean men (age range: 40-79 years) registered in the Korea National Health Insurance Service database from 2002 through 2013. We compared HRs for pterygium between 90547 current/past and 90547 never-smokers via 1:1 propensity-matched analysis.

Primary outcome measure Incident cases of pterygium were identified from the database.

Results Pterygium developed in $5389(6.0 \%)$ neversmokers and 3898 (4.3\%) past/current smokers $(\mathrm{P}<0.001)$. The incidence of pterygium per 1000 personyears in never-smokers and in past/current smokers was 6.5 and 4.7, respectively (age-adjusted HR, $0.73 ; 95 \% \mathrm{Cl}$, 0.70 to 0.76 ). This protective effect was more pronounced among current smokers than among past smokers (for current smokers: HR, $0.68 ; 95 \% \mathrm{Cl}, 0.65$ to 0.71 and for past smokers: $\mathrm{HR}, 0.85 ; 95 \% \mathrm{Cl}, 0.80$ to 0.90 ). A longer duration of smoking and higher amounts of cigarette consumption were associated with a lower incidence of pterygium.

Conclusions Longitudinally, cigarette smoking was associated with a reduced risk of pterygium, and this protective effect was more pronounced among current smokers than among past smokers.

\section{INTRODUCTION}

Cigarette smoking is considered one of the most important risk factors for a number of systemic diseases ${ }^{1}$ and eye diseases such as age-related macular degeneration, ${ }^{2}$ retinal vein occlusion ${ }^{3}$ and thyroid eye disease. ${ }^{4}$ However, for some diseases or conditions, inverse association was also reported: smoking seemed to relieve inflammatory bowel disease ${ }^{5}$; smoking was associated with decreased incidence of Parkinson disease ${ }^{6}$ and smokers seemed to have better short-term health outcomes than non-smokers following
Strengths and limitations of this study

- This study is unique because our study is the first large-scale longitudinal study to evaluate the temporal relationship between cigarette smoking and risks of pterygium.

- A lack of clinical information, including visual acuity, severity of pterygium and the eye affected, is an inherent limitation of the present claims database study.

- Last, we could not access data on sun exposure, which is one of the most important risk factors for pterygium. However, our detailed stratified matching allowed us to establish two comparable groups and eliminated the effect of confounding factors, such as sun exposure.

hospitalisation for heart attacks, a phenomenon also known as 'smoker's paradox' in cardiology. ${ }^{78}$

Pterygium is a triangular mass of thickened conjunctiva extending over the cornea that may cause a disturbance in vision. The association between smoking and pterygium has been investigated via cross-sectional studies, ${ }^{9-21}$ a propensity score-matched study ${ }^{22}$ and meta-analysis. ${ }^{23}$ Unlike most reports on the negative aspects of smoking in public health and the majority of systemic diseases, smoking has been repeatedly reported as a protective factor against the development of pterygium in cross-sectional studies, ${ }^{13-16}$ including one conducted in Korea. ${ }^{21}$

However, to establish a temporal relationship between cigarette smoking and the development of pterygium, a large, well-designed longitudinal cohort study is required. The National Health Insurance Service (NHIS) database in South Korea provides an adequate opportunity for the evaluation of the development of pterygium among the general population according to smoking status. Therefore, we evaluated 
the association between cigarette smoking and incident pterygium in a nationwide random sample comprising 181094 men from South Korea.

\section{METHODS}

\section{Ethics}

This retrospective cohort study adhered to the tenets of the Declaration of Helsinki, and the study design was approved by the institutional review board of the NHIS Ilsan Hospital, which waived the requirement for written informed consent.

\section{Database}

A unique national insurance system has been implemented in South Korea, covering approximately $97 \%$ of the nation's population. This study used a new dataset developed by the Korean NHIS and released for use in research for the first time in 2016: the National Health Screening Cohort (NHIS-HEALS).$^{24}$ The NHID includes approximately 510000 randomly selected individuals between the ages of 40-79 years, who were enrolled in the Korean National Health Screening Program in 2002 and 2003 ( 10\% of NHIS beneficiaries who had participated in a screening program). These selected participants were followed up until 2013. The database contains data regarding sociodemographic factors, medical examination results, interventions, prescription drugs and diagnostic codes for all medical care transactions from all types of medical facilities. Detailed cohort profiling has been described previously. ${ }^{24}$

\section{Study cohort}

Based on a previous report regarding the presence of a large proportion of unreported women smokers in Korea due to cultural and social barriers ${ }^{25}$ and because of the very low proportion of women smokers $(3.9 \%)$ in the NHID database, we included only men in this study. Therefore, the study cohort included men enrolled in the National Health Screening Program between 2002 and 2003 who met the following eligibility criteria: (1) response to questions regarding smoking status; (2) age between 40 and 79 years in 2002 (the lower and upper limits were set based on those of the database) and (3) clinical data for continuous variables including body mass index, blood pressure and other parameters (except age) within the top and bottom 1\%. Patients with pterygium in 2002 and 2003 were excluded. A detailed diagram of the study population is shown in figure 1 . We performed propensity matching of the study cohort according to propensity scores based on 38 potential baseline confounders, including age, income level, area of residence, medical history and examination results, history of prescription-drug use and antihypertensive medication and utilisation of eye care (table 1). Details regarding diagnosis codes for comorbidity are provided in online supplementary table 1 . Sociodemographic factors such as income level or residence area were identified as one of the strongest predictors for pterygium in previous

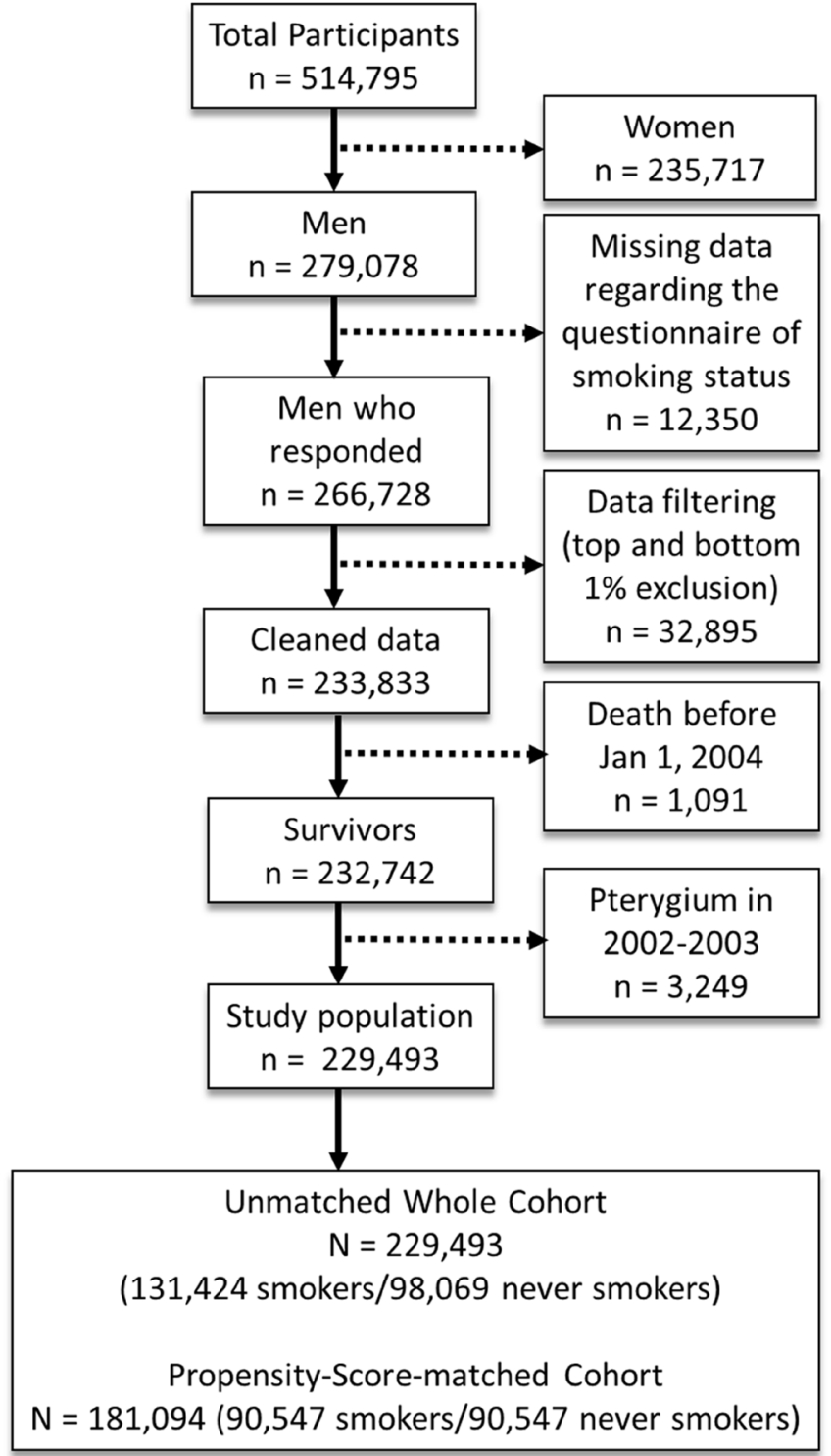

Figure 1 Flow chart of participant selection.

studies. ${ }^{9-21}$ All Korean citizens were categorised as insured employees, insured self-employed individuals or medical aid beneficiaries. This database provided subjects' income levels in 10 percentiles for insured employees, 10 percentiles for insured self-employed and the lowest level of income for medical aid beneficiaries, in a total of 21 levels. However, since the proportion of medical aid beneficiaries were very small, we combined the lowest level of 10 percentiles from insured self-employed group and medical aid beneficiaries group. Geographically, South Korea could be divided into 16 different provinces. Therefore, we stratified income level using a 20-level categorisation and area of residence using 16-level categorisation. Korean citizens who were covered under NHIS were categorised as insured employees, insured self-employed individuals and Medical Aid beneficiaries. Income among insured employees was categorised into income levels 1-10, while income among insured self-employed individuals was categorised into 
Table 1 Baseline characteristics of the study participants (smokers vs never-smokers matched using propensity score matching)

\begin{tabular}{|c|c|c|c|}
\hline \multirow[b]{2}{*}{ Characteristic } & \multicolumn{3}{|c|}{ Propensity-score-matched cohort $(n=181094)$} \\
\hline & $\begin{array}{l}\text { Never-smoker cohort } \\
(n=90547)\end{array}$ & $\begin{array}{l}\text { Smoker cohort (past and } \\
\text { current) ( } n=90547)\end{array}$ & P Value \\
\hline Pterygium-no. (\%) & $5389(6.0)$ & $3898(4.3)$ & $<0.001$ \\
\hline Age (years) & $52.3 \pm 9.2$ & $52.3 \pm 9.2$ & 0.338 \\
\hline Body mass index $\left(\mathrm{kg} / \mathrm{cm}^{2}\right)$ & $2.6 \pm 17.6$ & $24.1 \pm 2.6$ & 0.202 \\
\hline Systolic blood pressure $(\mathrm{mm} \mathrm{Hg})$ & $128.5 \pm 16.3$ & $128.5 \pm 16.4$ & 0.766 \\
\hline Diastolic blood pressure $(\mathrm{mm} \mathrm{Hg})$ & $81.1 \pm 10.6$ & $81.1 \pm 10.5$ & 0.391 \\
\hline Fasting glucose & $97.5 \pm 22.6$ & $97.6 \pm 22.9$ & 0.314 \\
\hline Total cholesterol & $198.0 \pm 33.8$ & $198.0 \pm 33.9$ & 0.981 \\
\hline Haemoglobin & $14.8 \pm 1.1$ & $14.8 \pm 1.1$ & 0.099 \\
\hline Aspartate aminotransferase & $27.2 \pm 9.5$ & $27.2 \pm 9.7$ & 0.495 \\
\hline Alanine transaminase & $27.8 \pm 14.1$ & $27.7 \pm 14.0$ & 0.228 \\
\hline Charlson's Comorbidity Index & $0.5 \pm 1.0$ & $0.5 \pm 1.0$ & 0.880 \\
\hline Mean number of eye care use in $2002-2003$ & $1.1 \pm 0.3$ & $1.1 \pm 0.3$ & 0.778 \\
\hline Hypertension-no. (\%) & $13229(14.6)$ & $13216(14.6)$ & 0.931 \\
\hline Hyperlipidaemia-no. (\%) & $4498(5.0)$ & $4502(5.0)$ & 0.966 \\
\hline Acute myocardial infarction-no. (\%) & $336(0.4)$ & $328(0.4)$ & 0.756 \\
\hline Heart failure-no. (\%) & $1974(2.2)$ & $1967(2.2)$ & 0.910 \\
\hline Peripheral vascular disease-no. (\%) & $954(1.1)$ & $922(1.0)$ & 0.458 \\
\hline Cerebrovascular disease-no. (\%) & $1431(1.6)$ & $1448(1.6)$ & 0.749 \\
\hline Chronic pulmonary disease-no. (\%) & $5965(6.6)$ & $5943(6.6)$ & 0.835 \\
\hline Liver diseases - no. (\%) & $5990(6.6)$ & $5997(6.6)$ & 0.947 \\
\hline Uncomplicated diabetes -no. (\%) & $5170(5.7)$ & $5162(5.7)$ & 0.935 \\
\hline Complicated diabetes -no. (\%) & $1585(1.8)$ & $1592(1.8)$ & 0.900 \\
\hline Cancer-no. (\%) & $1372(1.5)$ & $1343(1.5)$ & 0.575 \\
\hline \multicolumn{4}{|l|}{ Prescription-drug use in $2002-2003-$ no. (\%) } \\
\hline \multicolumn{4}{|l|}{ Antidiabetes mellitus medication } \\
\hline Metformin & $2627(2.9)$ & $2648(2.9)$ & 0.769 \\
\hline Sulfonylurea & $3817(4.2)$ & $3821(4.2)$ & 0.963 \\
\hline Meglitinide & $128(0.1)$ & $132(0.2)$ & 0.804 \\
\hline Thiazolidinedione & $91(0.1)$ & $85(0.1)$ & 0.651 \\
\hline Alpha Glucosidase Inhibitors & $1212(1.3)$ & $1219(1.4)$ & 0.886 \\
\hline Insulin & $52(0.1)$ & $52(0.1)$ & $>0.999$ \\
\hline \multicolumn{4}{|l|}{ Antihypertensives } \\
\hline Angiotensin II receptor antagonist & $3599(4.0)$ & $3573(4.0)$ & 0.754 \\
\hline Angiotensin-converting-enzyme inhibitor & $6762(7.5)$ & $6814(7.5)$ & 0.643 \\
\hline Calcium channel blocker & $11807(13.0)$ & $11770(13.0)$ & 0.796 \\
\hline Diuretics & $7625(8.4)$ & $7600(8.4)$ & 0.832 \\
\hline Beta-blocker & $7685(8.5)$ & $7666(8.5)$ & 0.873 \\
\hline Others & $1050(1.2)$ & $1032(1.1)$ & 0.692 \\
\hline Statins & $3647(4.0)$ & $3626(4.0)$ & 0.802 \\
\hline Aspirin & $1851(2.0)$ & $1877(2.1)$ & 0.667 \\
\hline
\end{tabular}

Comparisons were made using t-tests and $\chi^{2}$-square tests for continuous and for categorical variables, respectively. 
income levels 11-20. Income among Medical Aid beneficiaries was categorised as income level 1 .

\section{Smoking status and validation}

The Korean National Health Screening Program employed a standardised questionnaire for smoking status (see online supplementary document 1). Participants were classified according to smoking status as never-smokers or smokers. Smokers were classified as either past or current smokers. For subgroup analyses, we also collected data regarding the duration of smoking $(\leq 9,10-29$ or $\geq 30$ years $)$ and daily cigarette consumption $(<10,10-19,20-29$ or $\geq 30$ cigarettes $)$.

To verify the smoking status of self-reported neversmokers during 2008-2013, we determined the proportion of men who had reported being current or past smokers during 2002-2007. A total of 61210 men had reported being never-smokers more than once during 2008-2013, of whom 47178 (77.1\%) had reported being never-smokers more than once during 2002-2007 as well. Therefore, smoking status was largely consistent over time. $^{26}$

\section{Follow-up and primary end points}

Participants enrolled between 2002 and 2003 were followed up from 1 January 2004 until the first date on which one of the following had occurred: loss to follow-up due to disqualification from NHIS (mainly death), incidence of pterygium in any eye or last visit to any medical care facility within the study period (31 December 2013). The primary end-point of the study was the incidence of pterygium. Cases of pterygium were defined based on an ophthalmologist's examination and claims with the Korean Classification of Diseases code for pterygium (H110; corresponding to 372.4 from the International Classification of Diseases, Ninth Revision, Clinical Modification). Incident pterygium was defined based on the person rather than based on the eye. ${ }^{27}$ We defined an incident case as the first diagnosis of pterygium in any eye regardless of the right or left side of the eye.

\section{Statistical analysis}

We developed propensity models using logistic regression for smokers (past and current) compared with never-smokers. Individual propensities for smokers were estimated via logistic regression analysis of 38 potential confounders (table 1). Smokers and never-smokers were then matched according to propensity scores in a 1:1 ratio based on $8 \rightarrow 1$ digit matching. We performed descriptive statistical analysis of propensity-matched cohorts to estimate the incidence of pterygium per 1000 personyears. Cox regression models were used to estimate HRs. Data of the propensity-matched cohort were evaluated via age-adjusted analysis. The cumulative incidence of pterygium from 1 January 12004 to 31 December 2013 was described using a Kaplan-Meier survival curve. Cox proportional hazards analysis of the duration of smoking

Table 2 Incidence of pterygium in smokers and non-smokers

\begin{tabular}{|c|c|c|}
\hline \multirow[b]{2}{*}{ Analysis } & \multicolumn{2}{|c|}{ Propensity-score-matched cohort $(n=181094)$} \\
\hline & Never smokers $(n=90547)$ & Smokers (past and current) $(n=90547)$ \\
\hline \multicolumn{3}{|l|}{ Primary analysis } \\
\hline Total follow-up (PYs) & 826493 & 823592 \\
\hline No. of pterygium & 5389 & 3898 \\
\hline Incidence (no./1000 PYs, 95\% Cl) & 6.5 & 4.7 \\
\hline Age-adjusted HR ( $95 \%$ Cl) & 1 (reference) & $0.73(0.70$ to 0.76$)$ \\
\hline$P$ Value & & $<0.001$ \\
\hline \multicolumn{3}{|l|}{ Subgroup analysis } \\
\hline \multicolumn{3}{|l|}{ Age 40-59 years } \\
\hline Total follow-up (PYs) & 641801 & 642005 \\
\hline No. of pterygium & 3874 & 2717 \\
\hline Incidence (no./1000 PYs, 95\% Cl) & 6.0 & 4.2 \\
\hline Age-adjusted HR ( $95 \% \mathrm{Cl})$ & 1 (reference) & $0.70(0.67$ to 0.74$)$ \\
\hline$P$ Value & & $<0.001$ \\
\hline \multicolumn{3}{|l|}{ Age 60-79years } \\
\hline Total follow-up (PYs) & 184692 & 181587 \\
\hline No. of pterygium & 1515 & 1181 \\
\hline Incidence (no./1000 PYs, 95\% Cl) & 8.2 & 6.5 \\
\hline Age-adjusted HR ( $95 \% \mathrm{Cl})$ & 1 (reference) & 0.79 (0.73 to 0.85$)$ \\
\hline$P$ Value & & $<0.001$ \\
\hline
\end{tabular}

PYs, person-years. 

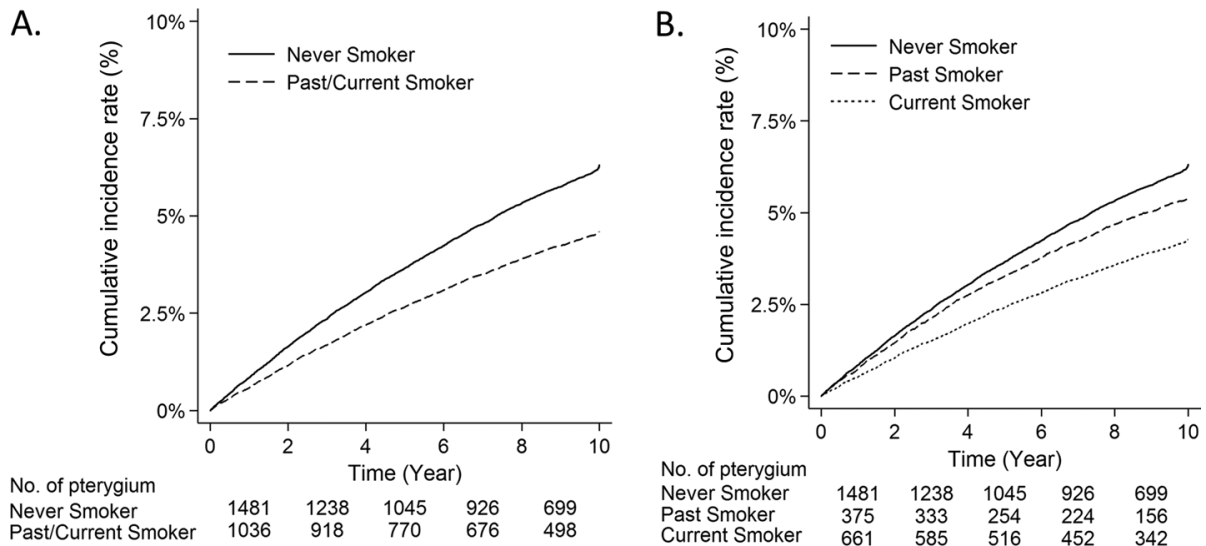

Figure 2 Cumulative incidence of pterygium among smokers and never-smokers between 1 January 2004 and 31 December 2013. We observed significant differences in the cumulative incidence of pterygium between smokers and never-smokers included in a retrospective cohort derived from a National General Health Screening Program conducted between 2002 and 2013 (A and B).

was performed according to 1-year age strata in order to account for immortal-time bias. The association between daily cigarette consumption and pterygium was evaluated via age-adjusted analysis. Proportional-hazard assumption for Cox regression was verified using the plot of $\log (-\log )$; graphs showed no indication of violation. For sensitivity analysis, data of the whole cohort were evaluated via propensity-adjusted analysis according to deciles of propensity scores and age. The level of statistical significance was set at $\mathrm{P}<0.05$. Analyses were performed using SAS System for Windows V.9.4 (SAS Institute, Cary, North Carolina, USA) and Stata/MP V.14.0 (StataCorp, College Station, Texas, USA).

\section{RESULTS}

\section{Characteristics of the study cohort}

A total of 181094 men met the inclusion criteria, including 90547 never-smokers and 90547 past/current smokers (table 1). Patient demographic and clinical characteristics in the whole unmatched cohort $(n=229493)$ varied greatly between the two groups; these data are provided in online supplementary table 2 . In the propensity-matched cohort, all variables, except the incidence of pterygium, were similar between the two cohorts: pterygium developed in 5389 never-smokers and 3898 smokers $(\mathrm{P}<0.001)$. Detailed comparisons between the two groups based on the 20 income strata and 16 area of residence strata are provided in online supplementary table 3. Income and area of residence were similar between the two groups.

\section{Incidence of pterygium}

Table 2 presents the HRs for pterygium for the propensity score-matched cohorts. The risk of pterygium among smokers was significantly lower than among neversmokers in propensity-matched cohorts (age-adjusted HR, $0.73 ; 95 \%$ CI, 0.70 to 0.76 ). The risk of pterygium in age subgroups (40-59 and 60-79 years) exhibited a similar trend; however, HRs for the older age-subgroup were greater than those for the younger age-subgroup (HR: younger cohort, 0.70; older cohort, 0.79). The Kaplan-Meier survival curve demonstrated a clear difference in the incidence of pterygium between smokers and never-smokers (figure 2A).

In table 3, HRs for past smokers were lower than those for never-smokers and greater than those for current smokers in the age-adjusted model (HR: past smokers, 0.85 ; current smokers, 0.68 ). This trend was also reflected in the survival curve for the cumulative incidence of

Table 3 Incidence of pterygium in smokers and non-smokers

\begin{tabular}{|c|c|c|c|}
\hline & \multicolumn{3}{|c|}{ Propensity-score-matched analysis $(n=181094)$} \\
\hline & \multirow{2}{*}{$\begin{array}{l}\text { Never-smoker } \\
(n=90547)\end{array}$} & \multicolumn{2}{|l|}{ Smoker } \\
\hline & & Past smoker $(n=26152)$ & Current smoker $(n=64395)$ \\
\hline No. of pterygium & 5389 & 1342 & 2556 \\
\hline Incidence (no./1000 PYs, 95\% Cl) & 6.5 & 5.6 & 4.4 \\
\hline P Value & & $<0.001$ & $<0.001$ \\
\hline$P$ for trends & \multicolumn{3}{|c|}{$<0.001$} \\
\hline
\end{tabular}

PYs, person-years. 


\begin{tabular}{|c|c|c|c|c|c|}
\hline Smoking status & No. of cases & Crude \% & HR & $95 \% \mathrm{Cl}$ & P Value \\
\hline \multicolumn{6}{|c|}{ Duration of smoking ( $n=181094)$} \\
\hline Never smoked & $5389 / 90547$ & 5.93 & 1 (reference) & & \\
\hline$\leq 9$ years & $503 / 10835$ & 4.68 & 0.81 & 0.74 to 0.89 & $<0.001$ \\
\hline $10-19$ years & $837 / 22625$ & 3.69 & 0.69 & 0.64 to 0.74 & $<0.001$ \\
\hline 20-29 years & $1133 / 28937$ & 3.78 & 0.70 & 0.65 to 0.74 & $<0.001$ \\
\hline$\geq 30$ years & $1425 / 28150$ & 5.05 & 0.75 & 0.71 to 0.80 & $<0.001$ \\
\hline \multicolumn{6}{|c|}{ Daily consumption of cigarette $(n=154942)$} \\
\hline Never smoked & $5389 / 90547$ & 5.98 & 1 (reference) & & \\
\hline$<10$ cigarettes & $670 / 15791$ & 4.73 & 0.69 & 0.64 to 0.75 & $<0.001$ \\
\hline 10-19 cigarettes & $1342 / 34533$ & 3.68 & 0.67 & 0.63 to 0.71 & $<0.001$ \\
\hline$\geq 20$ cigarettes & $544 / 14071$ & 3.65 & 0.68 & 0.62 to 0.74 & $<0.001$ \\
\hline
\end{tabular}

We performed age-stratified analyses for the duration of smoking and pterygium as well as age-adjusted analyses for daily consumption of cigarettes and pterygium. Persons with missing data regarding daily cigarette consumption were excluded.

pterygium: the survival curve of past smokers was located between those of never-smokers and current smokers (figure 2B).

Table 4 shows subgroup analyses of smoking for the risk of pterygium. In the 1-year age-stratified Cox model, men who smoked for 10-19, 20-29 and $\geq 30$ years were less likely to have pterygium than never-smokers (HR, 0.69, 0.70 and 0.75 , respectively). Similar negative association was observed in terms of daily cigarette consumption: men who smoked $<10,10-19$ and $\geq 20$ cigarettes daily were less likely to have pterygium than never-smokers (HR, $0.69,0.67$ and 0.68 , respectively). In sensitivity analyses of the unmatched cohort using propensity score-adjusted analysis, the multivariable-adjusted HR for pterygium for smokers was 0.72 (95\% CI, 69 to 0.75 ) (see online supplementary table 4$)$.

\section{DISCUSSION}

To our knowledge, our study is the first large-scale longitudinal study to evaluate the temporal relationship between cigarette smoking and risks of pterygium in a nationwide sample of 181094 Korean men. We confirmed the protective effect of smoking against the prospective development of pterygium in a historical cohort. This effect was more pronounced in current smokers than in past smokers and was surprisingly greater in men who smoked more than in those who smoked less. Our results are noteworthy because various conditions were controlled, including age, income level, area of residence, health examination variables, comorbidities, drug use and frequency of eye care utilisation.

Previous cross-sectional studies have reported inconsistent results regarding the prevalence of pterygium in individuals who smoke. Among the Chinese population in Singapore, smoking was associated with a higher risk of pterygium in univariate analysis; however, in a model with age, sex, occupation and smoking as covariates, no such association was observed. ${ }^{17}$ Among the Malay population in Singapore, bilateral pterygium was marginally associated with smoking (OR, 1.5; 95\% CI, 1.0 to 2.2). However, no type of pterygium (in one eye or both eyes) was significantly associated with smoking (OR, 1.2; 95\% CI, 0.9 to 1.5$).{ }^{11}$ Similarly, a more recent pooled analysis of the three major ethnic groups in Singapore revealed no significant association between smoking and pterygium/ severe pterygium. ${ }^{20}$ In a previous cross-sectional study conducted in South Korea, ${ }^{21}$ analyses revealed somewhat different results depending on the method used to control for other variables, such as sociodemographic factors: in unadjusted analyses, longer duration of smoking was associated with an increased risk of pterygium; however, in adjusted analyses including sociodemographic factors and sun exposure as factors, the opposite finding was observed. Finally, in a multivariable model, lifetime smokers had a lower prevalence of pterygium compared with never-smokers (OR, $0.7 ; 95 \% \mathrm{CI}, 0.6$ to 0.9$)$. This also highlights the importance of proper control for other sociodemographic factors in a cross-sectional study. ${ }^{21}$

The Barbados Eye Study, which included a predominantly African Caribbean population living in an area with very different climate and race compared with the above-mentioned Asian countries, also reported the protective effect of smoking on pterygium. However, an early cross-sectional study performed in 2001 reported a low prevalence of pterygium among current smokers (OR, 0.62; $95 \% \mathrm{CI}, 0.41$ to 0.94$),{ }^{13}$ while a later longitudinal study reported a relatively weaker protective effect (OR, $0.82 ; 95 \% \mathrm{CI}, 0.48$ to 1.39$).^{28}$

The mechanism underlying the protective effect of smoking on pterygium remains somewhat unclear. Such effects may be explained by vasoconstriction or suppression of inflammatory cytokines induced by nicotine as well as alterations in the tear film such as increases in levels of secreted antibodies. However, as our epidemiological 
study could not provide any evidence regarding this matter, further studies are required to more fully elucidate the mechanism underlying the development of pterygium.

This study has several limitations. First, we had no access to data on the severity of pterygium or the eye affected (right, left or both). Second, it is possible that self-reported smoking habits are underestimated. However, this misclassification bias would lead to the underestimation of the true association between smoking and pterygium. However, it is possible that delayed diagnosis resulted in underestimation of pterygium incidence in the present study. Third, we also considered the possibility that the study population included in the health screening databases may have been biased relative to general population-based controls, who may not have received national general health screening. it is also possible that these biases were similar among smokers and never-smokers. To minimise selection or surveillance bias, we controlled for 38 possible confounding factors, including eye care utilisation. To minimise the immortal time bias, we performed a 1-year age-stratified analysis to estimate the association between duration of smoking and pterygium. Fourth, we could not access data on sun exposure, which is one of the most important risk factors for pterygium. However, we performed a detailed stratified matching of sociodemographic factors, including 20 strata for income level and 16 strata for area of residence, between smokers and never-smokers. This stratified matching allowed us to establish two comparable groups while eliminating the effect of confounding factors such as sun exposure. In addition, our results should be generalised with some caution, as this study was limited to East Asian men only.

In conclusion, our longitudinal study revealed a temporal relationship between cigarette smoking and subsequent lower incidence of pterygium. This protective effect was more pronounced among current smokers than among past smokers. We also found a low risk of pterygium in smokers, after dividing smoking by duration or intensity. Unlike the negative aspects of smoking in public health and various diseases, cigarette smoking may have an unexpected protective effect on the development of pterygium.

\footnotetext{
Author affiliations

${ }^{1}$ Department of Ophthalmology, Severance Hospital, Institute of Vision Research, Yonsei University College of Medicine, Seoul, Korea

${ }^{2}$ Department of Policy Research Affairs, National Health Insurance Service Ilsan Hospital, Goyang, Korea

${ }^{3}$ Ophthalmology \& Visual Sciences Academic Clinical Program (Eye ACP), Duke-NUS Medical School, Singapore, Singapore

${ }^{4}$ Singapore Eye Research Institute, Singapore National Eye Centre, Singapore, Singapore

${ }^{5}$ Department of Ophthalmology, Yong Loo Lin School of Medicine, National University of Singapore, Singapore, Singapore

${ }^{6}$ Yonsei Healthcare Big Data Based Knowledge Integration System Research Center, Yonsei University College of Medicine, Seoul, Korea

${ }^{7}$ Institute of Convergence Science, Yonsei University College of Medicine, Seoul, Korea
}

Acknowledgements This study used data from the NHIS-NCS 2002-2013 (NHIS2017-2-293), which was released by the KNHIS.

Contributors Conception and design: THR, DWK, CYC and SSK. Analysis and interpretation: THR, DWK, CYC and SSK. Data collection: THR, DWK, CYC and SSK. Manuscript preparation: THR, CYC and SSK. Overall responsibility: SSK.

Disclaimer The authors alone are responsible for the content and writing of this article. SSK had full access to all of the data in the study and takes responsibility for the integrity of the data and the accuracy of the data analysis.

\section{Competing interests None declared.}

Patient consent Detail has been removed from this case description/these case descriptions to ensure anonymity. The editors and reviewers have seen the detailed information available and are satisfied that the information backs up the case the authors are making.

Ethics approval The institutional review board of the NHIS IIsan Hospital.

Provenance and peer review Not commissioned; externally peer reviewed.

Data sharing statement Access to NHIS-NSC data are available from the website of NHIS (https://nhiss.nhis.or.kr) after completing the application process and receiving approval (http://nhiss.nhis.or.kr/bd/ab/bdaba021eng.do). Detailed cohort profile and the methods for obtaining data are explained in the following source: Lee J, Lee JS, Park SH, Shin SA, Kim K. Cohort Profile: The National Health Insurance Service-National Sample Cohort (NHIS-NSC), South Korea. International journal of epidemiology. 2016. doi: 10.1093/ije/dyv319. PubMed PMID: 26822938.

Open Access This is an Open Access article distributed in accordance with the Creative Commons Attribution Non Commercial (CC BY-NC 4.0) license, which permits others to distribute, remix, adapt, build upon this work non-commercially, and license their derivative works on different terms, provided the original work is properly cited and the use is non-commercial. See: http://creativecommons.org/ licenses/by-nc/4.0/

(C) Article author(s) (or their employer(s) unless otherwise stated in the text of the article) 2017. All rights reserved. No commercial use is permitted unless otherwise expressly granted.

\section{REFERENCES}

1. Bilano V, Gilmour S, Moffiet T, et al. Global trends and projections for tobacco use, 1990-2025: an analysis of smoking indicators from the WHO Comprehensive Information Systems for Tobacco Control. Lancet 2015;385:966-76.

2. Seddon JM, Willett WC, Speizer FE, et al. A prospective study of cigarette smoking and age-related macular degeneration in women. JAMA 1996;276:1141-6.

3. Wong TY, Larsen EK, Klein R, et al. Cardiovascular risk factors for retinal vein occlusion and arteriolar emboli: the Atherosclerosis Risk in Communities \& Cardiovascular Health studies. Ophthalmology 2005;112:540-7.

4. Prummel MF, Wiersinga WM. Smoking and risk of Graves' disease. JAMA 1993;269:479-82.

5. Thole ME, Murray C, Erian G, et al. Influence of smoking and other environmental factors in inflammatory bowel disease activity: what do our patients think? Gastroenterology 2011;140:S790.

6. Sääksjärvi K, Knekt P, Männistö S, et al. Reduced risk of Parkinson's disease associated with lower body mass index and heavy leisuretime physical activity. Eur J Epidemiol 2014;29:285-92.

7. Ali SF, Smith EE, Bhatt DL, et al. Paradoxical association of smoking with in-hospital mortality among patients admitted with acute ischemic stroke. J Am Heart Assoc 2013;2:e000171.

8. Aune E, Røislien J, Mathisen M, et al. The "smoker's paradox" in patients with acute coronary syndrome: a systematic review. BMC Med 2011;9:97.

9. Rezvan F, Hashemi H, Emamian MH, et al. The prevalence and determinants of pterygium and pinguecula in an urban population in Shahroud, Iran. Acta Med Iran 2012;50:689-96.

10. Asokan R, Venkatasubbu RS, Velumuri L, et al. Prevalence and associated factors for pterygium and pinguecula in a South Indian population. Ophthalmic Physiol Opt 2012;32:39-44.

11. Cajucom-Uy H, Tong L, Wong TY, et al. The prevalence of and risk factors for pterygium in an urban Malay population: the Singapore Malay Eye Study (SiMES). Br J Ophthalmol 2010;94:977-81.

12. Shiroma H, Higa A, Sawaguchi S, et al. Prevalence and risk factors of pterygium in a southwestern island of Japan: the Kumejima Study. Am J Ophthalmol 2009;148:766-71. 
13. Luthra R, Nemesure BB, Wu SY, et al. Frequency and risk factors for pterygium in the Barbados Eye Study. Arch Ophthalmol 2001;119:1827-32.

14. West S, Muñoz B. Prevalence of pterygium in Latinos: Proyecto VER. Br J Ophthalmol 2009;93:1287-90.

15. Marmamula S, Khanna RC, Rao GN. Population-based assessment of prevalence and risk factors for pterygium in the South Indian state of Andhra Pradesh: the Andhra Pradesh Eye Disease Study. Invest Ophthalmol Vis Sci 2013;54:5359-66.

16. Gazzard G, Saw SM, Farook M, et al. Pterygium in Indonesia: prevalence, severity and risk factors. Br J Ophthalmol 2002;86:1341-6.

17. Wong TY, Foster PJ, Johnson GJ, et al. The prevalence and risk factors for pterygium in an adult Chinese population in Singapore: the Tanjong Pagar survey. Am J Ophthalmol 2001;131:176-83.

18. Sun LP, Lv W, Liang YB, et al. The prevalence of and risk factors associated with pterygium in a rural adult Chinese population: the Handan Eye Study. Ophthalmic Epidemiol 2013;20:148-54.

19. Tano T, Ono K, Hiratsuka Y, et al. Prevalence of pterygium in a population in Northern Japan: the Locomotive Syndrome and Health Outcome in Aizu Cohort Study. Acta Ophthalmol 2013;91:e232-e236.

20. Ang M, Li X, Wong W, et al. Prevalence of and racial differences in pterygium: a multiethnic population study in Asians. Ophthalmology 2012;119:1509-15.
21. Rim TH, Nam J, Kim EK, et al. Risk factors associated with pterygium and its subtypes in Korea: the Korean National Health and Nutrition Examination Survey 2008-2010. Cornea 2013;32:962-70.

22. Song E, Sun HP, Xu Y, et al. Cigarette smoking and pterygium: a propensity score matching analysis. Optom Vis Sci 2016;93:466-70.

23. Rong SS, Peng $Y$, Liang YB, et al. Does cigarette smoking alter the risk of pterygium? A systematic review and meta-analysis. Invest Ophthalmol Vis Sci 2014;55:6235-43.

24. Seong SC, Kim YY, Park SK, et al. Cohort profile: the National Health Insurance Service-National Health Screening Cohort (NHIS-HEALS) in Korea. BMJ Open 2017;7:7:e016640.

25. Jung-Choi $\mathrm{KH}$, Khang $\mathrm{YH}$, Cho HJ. Hidden female smokers in Asia: a comparison of self-reported with cotinine-verified smoking prevalence rates in representative national data from an Asian population. Tob Control 2012;21:536-42.

26 Rim TH, Cheng CY, Kim DW, et al. A nationwide cohort study of cigarette smoking and risk of neovascular age-related macular degeneration in East Asian men. Br J Ophthalmol 2017;101:1367-73.

27 Rim TH, Kang MJ, Choi M, et al. The incidence and prevalence of pterygium in South Korea: A 10-year population-based Korean cohort study. PLoS One 2017;12:e0171954.

28 Nemesure B, Wu SY, Hennis A, et al. Nine-year incidence and risk factors for pterygium in the barbados eye studies. Ophthalmology 2008;115:2153-8. 